\title{
Genetic analysis of very obese children with autism spectrum disorder
}

Herman D. Cortes and Rachel Wevrick*

Dept. of Medical Genetics, University of Alberta, Edmonton, Alberta Canada

*Corresponding author.

Authors:

Rachel Wevrick, Dept. of Medical Genetics, University of Alberta, Edmonton, Alberta Canada, rwevrick@ualberta.ca

Herman D. Cortes, Dept. of Medical Genetics, University of Alberta, Edmonton, Alberta Canada, hdc2@ualberta.ca

Running title: Syndromic autism with obesity in the SSC

Key words: SSC, autism spectrum disorder, obesity, Wnt, Gene Ontology 
Abstract: Autism spectrum disorder (ASD) is defined by the triad of deficits in social interactions, deficits in communication, and repetitive behaviors. Common co-morbidities in syndromic forms of ASD include intellectual disability, seizures, and obesity. We asked whether very obese children with ASD had different behavioral, physical and genetic characteristics compared to children with ASD who were not obese. We found that very obese children with ASD had significantly poorer scores on standardized behavioral tests. Very obese boys with ASD had lower full scale IQ and increased impairments with respect to stereotypies, communication and social skills. Very obese girls with ASD had increased impairments with respect to irritability and oppositional defiant behavior. We identified genetic lesions in a subset of the children with ASD and obesity and attempted to identify enriched biological pathways. Our study demonstrates the value of identifying co-morbidities in children with ASD as we move forward towards understanding the biological processes that contribute to this complex disorder and prepare to design customized treatments that target the diverse genetic lesions present in individuals with ASD. 


\section{Introduction}

Autism spectrum disorder (ASD) has complex origins with contributions from genetic and environmental factors. As more genes are identified in which sequence variants contribute to ASD predisposition, it can be useful to determine whether mutations in certain genes are responsible not only for ASD, but also for co-morbid conditions that define syndromic forms of ASD [1]. Fragile X syndrome, Angelman syndrome, Rett syndrome and a syndrome associated with POGZ mutations [2] are examples of syndromes with defined genetics that have high rates of behavioral phenotypes either fitting the definition of ASD or closely mimicking ASD [3]. Other syndromes with defined genetics and with elevated risks of ASD include Down syndrome [4], del16p11 syndrome [5], Bardet-Biedl syndrome [6], and Prader-Willi syndrome (PWS) [7]. However, in the latter syndromes, how the loss of specific genes confers increased risk of ASD is still unclear. For example, the expression of multiple contiguous genes is disrupted in PWS. However, mutations in only one of the inactivated genes, namely MAGEL2, cause a PWS-like syndrome called Schaaf-Yang syndrome [8-10]. Inactivating mutations in MAGEL2 also carry a very high risk of ASD, suggesting that loss of MAGEL2 also contributes to the increased incidence of ASD in children with PWS.

Children with ASD have an increased risk of overweight and obesity [11-14]. However, the genetic contribution to the co-morbidity of obesity in ASD has not been systematically studied $[15,16]$. While rising rates of obesity in adults have been attributed to societal changes in physical activity and food choices, severe childhood obesity more often involves changes in the central neural circuits that regulate food intake and energy expenditure [17]. In principle, ASD and obesity could co-occur in an individual because of a single inherited or sporadic genetic mutation (e.g. MAGEL2 deficiency), two inherited or sporadic genetic mutations (one gene responsible for ASD and a different gene responsible for obesity), or a combination of genetic mutations and multifactorial contributions. Indeed, a variety of circumstances such as reduced activity, access to health care, and interrupted sleep patterns may contribute to obesity in ASD probands $[12,14]$. Some probands could have an inherited predisposition to obesity that is unrelated to their ASD diagnosis, such as variation in the melanocortin-4 receptor or FTO genes [18].

ASD- and obesity-predetermining genes participate in a large variety of biological processes, many of which affect the function of central neural circuits. Proteins important for ion transport and chromatin remodeling are common sources of mutations in autism gene sets [19]. The planar cell polarity (PCP) and Wnt-beta catenin pathways that control cell polarity and adhesion have been implicated in both autism [20-22] and in the hypothalamic regulation of energy balance [23]. A key player is the ASD-associated gene CTNNB1, encoding beta catenin, in which mutations cause 
intellectual disability (ID)/ASD with neonatal hypotonia and respiratory problems [24, 25]. Mutations in a set of genes important for PCP pathways and ciliary function cause Bardet-Biedl syndrome, a neurodevelopmental disorder associated with intellectual disability and obesity [26].

An excess of de novo copy number variants (dnCNVs) in probands (0.05 per individual) compared to siblings ( 0.02 per individual) and a larger number of genes contained within proband dnCNVs compared to sibling dnCNVs are found in autism cohorts, suggesting that dnCNVs are associated with risk of ASD [27]. Whole exome sequencing studies have estimated an average of 0.17 de novo likely gene disrupting (dnLGD) and 0.94 de novo non-synonymous coding mutations (dnNSC) per affected child, also in excess over the de novo events in the control siblings [27, 28]. Most recent estimates have implicated at least $8 \mathrm{CNVs}$ and 65 genes with increased risk for ASD [29]. We hypothesized that candidate genes for ASD with severe obesity could be identified by analyzing genetic variants found in very obese children with ASD from the Simons Simplex Collection (SSC) [30].

\section{Methods}

Probands and siblings: At the time of study, the SSC Version 15 Phenotype Data Set 9 contained data on 2873 probands with ASD, their parents, and one or more siblings [31]. The data include psychological and IQ testing, medical history, dysmorphology, birth order, and anthropometric information. Details of phenotypic data are available from SFARI Base (sfari.org/resources/autismcohorts/simons-simplex-collection). Height Z-score, body mass index (BMI), and BMI Z-score were drawn from the SSC dataset for each proband and designated unaffected sibling. As with height, normal ranges of BMI vary with age in children, so the use of Z-scores rather than absolute values allowed standardized comparison of children from 3 to 18 years of age. Height-Z and BMI-Z scores were pre-calculated in the SSC dataset using the World Health Organization growth standards and the age at evaluation from the SSC "Height, Weight, and Head Circumference" form.

Genes: Genetic mutations in SSC probands were derived from data in GPF: Genotype and Phenotype in Families [32]. Constraint scores defining tolerance to genetic mutation were derived from Exome Aggregation Consortium (ExAC) data [33]. Intolerance to mutation is assumed when the observed number of mutations (missense or loss of function) is significantly less than the number of mutations expected.

Statistics: Comparisons between groups of probands were performed by Student t-test followed by post-hoc comparisons with Bonferroni corrections and a value of $P<0.05$ for significance. Data in Table 1 were analyzed by Student t-test. Data in Table 2 were analyzed by the PANTHER Overrepresentation Test (release 20170413) using a Bonferroni post hoc correction for multiple testing 
[34]. The correlation between birth order and full scale IQ was calculated by the Pearson method. Fisher's exact test was used to compare the mean BMI-Z and height-Z scores of probands vs unaffected siblings.

\section{Results}

Relationships between body mass index and anthropometric measurements, IQ, and neonatal history in SSC probands. We assessed the relationships between BMI and other anthropometric measurements, IQ, behavior, and neonatal history in the SSC SFARI Base, which contains data on probands with ASD, their parents, and siblings when available [31]. Age, height-Z, and BMI-Z scores were available for 2246 male probands and 338 female probands (Fig. 1). The mean BMI-Z of probands $(0.66 \pm 1.38$, mean $\pm \mathrm{SD})$ was slightly larger than that of unaffected siblings $(0.55 \pm 1.27$, Student t-test, $P=0.01)$. More probands than siblings had a BMI-Z $\geq 2$ (18\% vs. 13\%, Fisher's exact test, $P<0.0001)$. These data are consistent with previous reports of increased risk of obesity in children with ASD [11-14]. Mean height-Z of probands (0.4 \pm 1.1 for males and $0.2 \pm 1.2$ for females) was similar to that of unaffected siblings (Student t-test).

Mother's BMIs (mean $27 \pm 7 \mathrm{~kg} / \mathrm{m}^{2}$ ) and father's BMIs (mean $29 \pm 6 \mathrm{~kg} / \mathrm{m}^{2}$ ) were calculated from their weight and height when available. Both weight and height have large genetic and environmental components, so we expected that probands with higher BMI would have parent(s) with higher BMI. Consistent with this prediction, $7 \%$ of obese probands with BMI-Z $\geq 2$ had one or two severely obese parents $(\mathrm{BMI} \geq 35)$, whereas $2.5 \%$ of probands with $-2 \leq \mathrm{BMI}-\mathrm{Z} \leq 2$ had one or two severely obese parents. This suggests that some probands with high BMI for age have an inherited predisposition to obesity, while others, particularly those with normal weight parents and siblings, may also carry deleterious mutations in obesity-predisposing genes.

We next tested whether there is a relationship between BMI-Z, ASD symptoms and full scale IQ (FSIQ) among SSC probands. In females, BMI-Z and FSIQ were not correlated. However, compared to typical weight males $(-2 \leq \mathrm{BMI}-\mathrm{Z} \leq 2)$, mean FSIQ was 12 points lower among very obese males (BMI-Z $\geq 3$ ) (Table 1). Obese male probands (BMI-Z $\geq 2$ ) and underweight male probands (BMI$\mathrm{Z} \leq-2$ ) also had significantly lower FSIQ than typical weight males. Verbal IQ was 13 points lower in very obese males compared to typical weight males. Consistent with a previous study [35], mean scores for some behaviors were worse in very obese compared to typical weight children with ASD: very obese males had increased impairments with respect to stereotypies on the Aberrant Behavior Checklist $(\mathrm{ABC})$, overall language on the Autism Diagnostic Interview (ADI), social problems, somatic problems 
and complaints, and total competence on the Child Behavior Checklist (CBCL 6-18), awareness and communication on the teacher version of the Social Responsiveness Scale, and in communication, daily living skills, and socialization on the Vineland Adaptive Behavior Rating Scales (VABS) (Fig. 2). Very obese females with ASD had larger impairments with respect to irritability (ABC) and aggressive and oppositional defiant behaviors (CBCL) compared to typical weight females (Fig. 2). It is important to note that many of these measures are correlated with each other: for example, lower IQ is correlated with increased stereotypies [36]. There were no behaviors that were less impaired in the very obese group in any of the scales used.

\section{Table 1. FSIQ (mean \pm SD) and BMI-Z in male probands.}

\begin{tabular}{|l|l|l|l|}
\hline Group & BMI-Z & FSIQ & Verbal IQ \\
\hline Group 1 (typical, $\mathrm{n}=1778$ ) & $-2<\mathrm{BMI}-\mathrm{Z}<2$ & $83 \pm 28$ & $80 \pm 31$ \\
\hline Group 2 (very obese, $\mathrm{n}=110$ ) & $\mathrm{BMI}-\mathrm{Z} \geq 3$ & $72 \pm 29^{\$}$ & $67 \pm 33^{\$}$ \\
\hline Group 3 (obese, $\mathrm{n}=412$ ) & $\mathrm{BMI}-\mathrm{Z} \geq 2$ & $79 \pm 27^{*}$ & $75 \pm 31$ \\
\hline Group 4 (underweight, $\mathrm{n}=61$ ) & $\mathrm{BMI}-\mathrm{Z} \leq-2$ & $76 \pm 28^{\#}$ & $73 \pm 30$ \\
\hline
\end{tabular}

$* \mathrm{P}=0.002$ different from Group 1

$\# \mathrm{P}=0.05$ different from Group 1

$\$ \mathrm{P}<0.00002$ different from Group 1

In humans, increased paternal age correlates with an increased number of de novo mutations in offspring at about 2 mutations per year [37]. However, Sanders et al. found no evidence for a correlation between the number of de novo mutations per proband and parental age in the SSC. We examined paternal age in very obese SSC probands, using birth order as a surrogate index for parental age. Very obese male probands had a higher average birth order $(2.0 \pm 0.9)$ compared to typical weight male probands $(1.7 \pm 0.8, P<0.0001)$, and so are expected to have slightly older parents. However (see below), there was no evidence that very obese probands had more de novo mutations than probands of typical weight.

We next examined SSC phenotypic data to determine whether obese or very obese SSC probands had other clinical findings that could suggest a syndromic form of autism. We were particularly interested in neonatal history, given that neonatal hypotonia or difficulty feeding are found in many neurodevelopmental disorders. Of 2591 SSC probands, 19\% reported some neonatal complication (Fig. 3). The most common neonatal complications were difficulty feeding and respiratory problems (in 19\%), poor suck (10\%), or decreased muscle tone (7\%). APGAR scores at 1 minute were reported to be below 7 in $5 \%$ of infants, and $7 \%$ were admitted to the NICU. These data 
represent minimum prevalence, as the absence of a report does not necessarily mean that the phenotype was not present. The prevalence of most neonatal complications was similar for probands who later presented as underweight (BMI-Z $\leq-2, n=66)$, obese (BMI-Z $\geq 2, n=465)$, or very obese (BMI-Z $\geq 3$, $\mathrm{n}=119$ ). There was a trend towards a higher incidence of "stiff infant" among the underweight class and a trend towards higher incidence of broken bones reported in the very obese class, but these trends were not statistically significant after accounting for multiple comparisons (Fig. 3).

\section{Genetic analysis of very obese probands in the SSC.}

We used GPF: Genotype and Phenotype in Families to identify de novo mutations in 133 probands with BMI-Z $\geq 3(10 \mathrm{~F}, 123 \mathrm{M})$ [32]. We limited the search to variant types sub, ins, del, or CNV with effect types coding (Nonsense, Frame-shift, Splice-site, Missense, Non-frame-shift, noStart, noEnd) or CNV (+ or -). There were 120 such de novo mutations, including 17 dnCNVs, 20 dnLGD, Frame-shift, Nonsense, or Splice-site) mutations and 83 mutations of the remaining varieties (Suppl. Table 1). The number of de novo mutations per very obese proband was not different from the number of de novo mutations per typical weight proband. Some probands had de novo mutations in more than one category. Three dnCNVs in very obese probands had already been associated with ASD risk [3841] (dup7q11, dup15q12, del16p11). Both the dup15q12 and del16p11 CNVs are also associated with obesity [42].

Analysis of loss of function mutations. Of the 20 genes with dnLGD mutations in very obese probands, 11 had already been associated with ASD in SFARI Gene [31] (ANK2, DNMT3A, DSCAML1, MYH10, POGZ, PPM1D, PSD3, PTK7), OMIM (VCP) or in neurodevelopmental disorders $[2,43](S P E N, S T A M)$. Only two of these genes have been associated with overgrowth: DNMT3A and POGZ. The proband identified here is the only one in the SSC with a dnLGD mutation in DNMT3A (DNA-methyltransferase 3 alpha). DNMT3A is mutated in children with Tatton-Brown-Rahman syndrome, which is associated with tall stature, a distinctive facial appearance, and intellectual disability. De novo inactivating mutations in $P O G Z$, encoding the chromatin factor Pogo transposable element with ZNF domain, cause syndromic autism with hypotonia and obesity (White-Sutton syndrome [2]). Only two probands in the SSC have dnLGD mutations in POGZ: the one identified here with $B M I-Z=3.6$ and another with $B M I-Z=2$, both consistent with White-Sutton syndrome. Inactivating mutations in PTK7 (encoding a tyrosine-protein kinase), and inherited or de novo mutations in PPM1D (encoding a protein phosphatase) have been found in children with ASD [27, 44]. The female with a PPM1D mutation also carries a dnNSC in SCN1A, encoding a sodium channel associated with epilepsy, and a dnLGD mutation in TNFRSF8. dnLGD mutations in MYH10 (encoding a non-muscle myosin) have been found in children with moderate to severe ID [44-47]. Heterozygous LGD 
mutations in $V C P$ (valosin containing protein) cause amyotrophic lateral sclerosis with dementia or myopathy [48]. The male with a $V C P$ dnLGD mutation also carried a dnNSC in $S C N 4 A$, a gene mutated in autosomal dominant and autosomal recessive muscular conditions. The other 10 genes in which dnLGD mutations were found have not been associated with neurodevelopmental genetic disorders to date. There were 83 dnNSC mutations, of which 20 are in genes plausibly associated with autism in SFARI gene (ANK3, CSMD1, DISC1, GLRA2, GRM7, KMT2C, MCC, NLGN2, PRKDC, PTK7, SCN1A, SCN4A, SLCO1B3, TRIP12, TTN, TUBGCP5, ZC3H4) or other neurodevelopmental disorders (ANO3, CNTN6, C9orf156, RYR1, SCN11A, SPEN, TAF6, TRPM6). Variants in ZC3H4 are also associated with uncontrolled eating [49], but otherwise none of the genes with dnNSC are associated with obesity.

Consideration of tolerance to mutation for ASD/obesity candidate genes. We next considered the tolerance of the candidate genes to either loss of function (LoF) or missense mutations using the ExAC interface [33]. Reduced tolerance would be expected of a gene for which haploinsufficiency reduces fertility, and would increase the likelihood that the de novo mutation is pathogenic. Of the genes with dnLGD mutations, ten previously identified ASD/ID genes were intolerant to LoF, missense or both (ANK2, DNMT3A, DSCAML1, MYH10, POGZ, PPM1D, PTK7, SPEN, STAM, and VCP). Of the remaining dnLGD genes, some were highly intolerant to LoF mutations (CDC23, SPAG9) or to missense mutations $(C D C 23)$ while the remaining were tolerant to both LoF and missense mutations. Of the genes in which there were dnNSC mutations in very obese probands, some were intolerant to either missense or LoF mutations, including genes associated with neurodevelopmental disorders (GLRA2, GRM7, KMT2C, MEGF8, PTK7, RYR1, SCN1A, TRIP12). Other genes not yet associated with disorders were also deemed intolerant to either missense or LoF mutations, while the remaining genes were either tolerant or of unknown tolerance (Suppl. Table 1).

Gene ontology pathways identifies proteins important for neuronal action potentials as contributors to ASD in very obese probands. We used Gene Ontology (GO) to identify pathways enriched in the de novo mutated gene set compared to expected for all GO-annotated genes in the genome [50]. This analysis is constrained by the fact that the very obese group differs from the typical weight group not only in high BMI-Z but also in lower IQ (Table 1) and more severe behavioral scores (Fig. 2), so that the genes mutated in this group may contribute to ASD or any one of these co-morbid phenotypes. The combined set of mutated genes (dnLGD and dnNSC) is significantly enriched in genes involved in neuronal membrane depolarization during action potential and voltage-gated ion channel activity (ANK2, ANK3, ANO9, ELK1, GLRA2, GRM7, NLGN2, RYR1, SCN1A, SCN3A, SCN4A, 
SCN11A, SLC17A3, TRPM6, VCP) (Table 2). Analysis of missense mutations alone produced a similar profile of disruption of neuronal action potential.

Table 2. Gene Ontology Consortium Enrichment Analysis.

\begin{tabular}{|c|c|c|}
\hline \multicolumn{1}{|c|}{ GO biological process complete } & $\begin{array}{c}\text { Fold } \\
\text { Enrichment }\end{array}$ & P value \\
\hline 1: neuronal action potential & 36 & 0.0003 \\
\hline 1a: regulation of membrane potential & 6 & 0.003 \\
\hline 2: membrane depolarization during action potential & 25 & 0.01 \\
\hline GO molecular function complete & & \\
\hline 3: voltage-gated sodium channel activity & 36 & 0.02 \\
\hline 3a: sodium channel activity & 30 & 0.004 \\
\hline $\begin{array}{c}\text { 3b: voltage-gated ion channel activity involved in regulation of postsynaptic } \\
\text { membrane potential }\end{array}$ & 58 & 0.003 \\
\hline 3bi: gated channel activity & 8 & 0.02 \\
\hline
\end{tabular}

Data were derived from PANTHER Overrepresentation Test (release 20170413), using the GO Ontology database released 2017-06-29, and a Bonferroni correction for multiple testing.

Planar cell polarity / Wnt signaling genes are also mutated in obese probands. We next investigated whether any of the mutated genes were previously implicated in obesity pathways. Intriguingly, all three SSC probands who carry de novo mutations in the PCP/Wnt pathway PTK7 gene [51] are very obese (Suppl. Table 2). PCP pathways intersect with phosphoinositide 3-kinase (PI3K) pathways, and 3 additional very obese probands carry de novo mutations in the PI3K pathway genes PSD3, MYH10, and $A N K 3$ respectively. We further investigated PCP/Wnt pathway genes in obese probands in the SSC (i.e. BMI-Z $\geq 2$ ). An obese SSC proband (BMI-Z=2.5) carries a dnLGD mutation in DVL3, one of the three human genes encoding forms of the Wnt relay protein Dishevelled [52]. This proband had neonatal feeding difficulties and physical anomalies including genital anomalies. Another obese SSC proband $(\mathrm{BMI}-\mathrm{Z}=2.5)$ carries a dnLGD mutation in NOTCH1, encoding a Dishevelled antagonist. This proband had neonatal feeding difficulties, and was stiff at birth, phenotypes also seen in infants with Adams-Oliver syndrome caused by NOTCH1 mutations [53]. CNTN6 encodes a NOTCH signaling pathway protein (contactin) and is mutated in a very obese proband [54]. Yet another obese SSC proband (BMI-Z=2.7) carries a dnLGD mutation in $M E D 13 L$, a gene associated with ID with transposition of the great arteries, and implicated in Wnt signaling [55]. This proband had neonatal respiratory distress, feeding difficulty, and other unspecified defects. Last, we looked at the DYRK1A gene, encoding a kinase that inactivates GSK3-beta and is implicated in neurodevelopmental disorders with co-morbid autism [56]. Of four probands in the SSC with DYRK1A mutations, three 
were obese and two had multiple neonatal complications. The Wnt/PCP genes PTK7, RAPGEF2, CTNNB1, DVL3, MED13L, DYRK1A, and NOTCH1 are all highly intolerant to LoF mutations, supporting their essential role in development. There were no loss of function mutations in the SSC collection in genes responsible for Bardet-Biedl syndrome, which is also a disorder of planar cell polarity. This is likely because children with Bardet-Biedl syndrome typically develop blindness and deafness, which would exclude them from the SSC.

We next considered a potential role for the $M U C$ genes in ASD with high BMI. The encoded mucin proteins are aberrantly regulated through Wnt-dependent pathways in tumors, particularly in cancers of the gastrointestinal tract. Variants in MUC5B are associated with type 2 diabetes [57]. Recurrent de novo nonsynonymous mutations in the MUC5B gene have previously been noted in cohorts of patients with autism or intellectual disability. However, MUC5B has been previously excluded as an ASD candidate gene because of high variation in controls [58]. In contrast, ExAC analysis suggests that $M U C 5 B$ is highly constrained for both missense and LoF mutations despite a high absolute number of variants in controls. All five probands in the SSC collection carrying MUC5B mutations had neonatal complications, and two were obese with BMI-Z=3.0 (missense mutation) and BMI-Z=2.9 (nonsense mutation) (Supplementary Table 3).

Last, genes encoding proteins important for endosomal sorting, protein ubiquitination and autophagy, pathways recently implicated in neurodevelopmental and neurodegenerative disorders [59] were also analyzed further. This analysis was motivated by the finding that mutations in the MAGEL2 gene cause ASD in Schaaf-Yang syndrome and contribute to obesity and ASD in Prader-Willi syndrome through disruption of endosomal protein trafficking [8-10, 60]. Genes associated with these pathways and mutated in very obese probands include VCP (valosin containing protein, mutations associated with ubiquitinated inclusions and protein aggregates in cells, frontotemporal dementia with myopathy, vesicle transport and fusion), STAM (component of the endosomal sorting complex), and SPAG9/JIP4 (kinesin-mediated transport in neurons).

\section{Discussion}

The Simons Simplex collection is a well-characterized cohort of individuals with autism spectrum disorder, for whom a rich variety of clinical data has also been collected. By its nature, individuals with ASD but also a diagnosis of a syndromic genetic disorder, such as Prader-Willi syndrome or Bardet-Biedl syndrome, are underrepresented in or excluded from SSC. As observed in other autism cohorts, probands in the SSC are overweight compared to unaffected siblings. We postulated that probands in the SSC at extreme ends of the phenotypic ranges for various traits could 
inform us about as yet unrecognized subtypes of ASD. Indeed, we found that very obese male SSC probands had lower full scale and verbal IQ compared to typical weight probands, and also had significantly worse scores in the areas of communication, daily living skills, and socialization. More severe behaviors were also seen in very obese female probands, but the smaller number of girls compared to boys represented in the SSC limited this analysis. We cannot exclude the possibility that being very obese in and of itself impairs social communication because of exclusion from activities with peers. Conversely, more severe behaviors could contribute to obesity because the child may be excluded from activities that promote fitness. Our study is also compromised by the considerable environmental contribution to the obesity phenotype, particularly in a country that has seen childhood obesity rates increase substantially in the last few decades. Limiting the analysis to very obese probands with two lean parents might have mitigated some of this confounding variable, but would have also reduced the sample size to an unmanageably small number of probands. We did not find that neonatal complications were associated with obesity in this study, although the lack of reporting of neonatal histories limited this analysis.

We proposed that genetic investigation of individuals with dual diagnoses of ASD and obesity could point us towards pathways that are essential for normal neurodevelopment and normal development of energy-regulating pathways. Our focus on de novo mutations in very obese probands correctly identified obesity predisposing lesions such as del16p11 and loss of function mutations in DNMT3A and POGZ and support a role for mutations in PTK7 in autism [40] and also in obesity. Additional very obese probands carried mutations in genes implicated in ASD or other neurological disorders, such as those important for neuronal action potentials, as predicted from previous autism analyses [61, 62]. Obese probands do not appear to have more pathogenic mutations compared to typical weight probands with ASD. Despite analyzing over 2000 probands, we could not determine whether some probands had mutations in two different genes or environmental factors that independently contributed to ASD and obesity. We also only examined de novo mutations, and so do not have information about other genetic mechanisms, such as recessive mutations that may contribute to either the obesity or ASD phenotypes.

The PCP/Wnt pathway has been implicated in neurodevelopmental disorders associated with neonatal complications and obesity, in part through the identification of key genes such as CTNNB1, MIB1, RAB23, MEGF8, PTK7, and the BBS genes in syndromic forms of intellectual disability. PTK7 encodes protein tyrosine kinase 7 and is implicated in Wnt signaling pathway. PTK7 (CCK4) binds intracellular scaffolding proteins of the Dishevelled family that act downstream of WNT receptors. PTK7 has mostly been studied in the context of cancer cell motility and in epithelial to mesenchymal 
transitions during development. A recessive Ptk7 mutation in mice (chuzhoi) causes severe developmental defects consistent with dysregulation of PCP, but no phenotype has been described in chuzhoi heterozygotes. Loss of ptk7 function in zebrafish causes ciliary and PCP abnormalities. In humans, we would not expect to find homozygous mutations, considering that this state is embryonic lethal in mice. It would however be interesting to determine whether chuzhoi heterozygous mice have behavioral abnormalities recapitulating ASD. The endosomal sorting/ubiquitination pathways have also been implicated in syndromic intellectual disability, with mutations in MAGEL2, VPS13B, and VCP causing syndromic neurological disorders. Our data support the previously noted involvement of both the PCP/Wnt pathway and the endosomal sorting /ubiquitination pathway in ASD. There are too few probands with obesity and ASD and de novo mutations to determine whether this pathway is indeed enriched in the very obese subgroup of children with ASD. Further investigation of these two pathways in ASD may be warranted. In particular, genes that are mutated in obese probands with ASD and in many cases also intolerant to mutation (BTBD9, DVL3, MED13L, RAPGEF2, RYK, STAM, and $S P A G 9)$ may be good candidates for involvement in syndromic forms of ASD.

\section{Conclusions.}

Our study provides a model for gene discovery using additional phenotypic information to categorize subsets of ASD probands. For example, probands with dysmorphic features could have a different set of genetic lesions compared to those without dysmorphic features. Extensive phenotypic characterization and collection of a larger cohort of children with ASD, as is now ongoing in the SPARK initiative [63] will enrich our understanding of the multitude of genes associated with the many flavors of autism spectrum disorder. This understanding is essential for the design of customized therapies that target the underlying genetic lesion that contributes to the diagnosis of ASD in each individual.

\section{List of Abbreviations}

Aberrant Behavior Checklist (ABC)

Autism Diagnostic Interview (ADI)

Autism spectrum disorder (ASD)

Body mass index (BMI),

Child Behavior Checklist (CBCL 6-18)

De novo copy number variants (dnCNVs)

De novo likely gene disrupting (dnLGD) 
De novo non-synonymous coding mutations (dnNSC)

Exome Aggregation Consortium (ExAC)

Full scale IQ (FSIQ)

Gene Ontology (GO)

Intellectual disability (ID)/

Loss of function (LoF)

Planar cell polarity (PCP)

Prader-Willi syndrome (PWS)

Simons Simplex Collection (SSC)

Vineland Adaptive Behavior Rating Scales (VABS)

\section{Declarations}

Ethics approval and consent to participate: Use of SSC data from human subjects was approved by the Health Research Ethics Board-Biomedical Panel of the University of Alberta, Edmonton, Alberta Canada.

Availability of data and material: The data that support the findings of this study are available from the Simons Foundation but restrictions apply to the availability of these data, which were used under license for the current study. Data are however available from the authors upon reasonable request and with permission of the Simons Foundation.

Funding: This work was supported by a grant from the Simons Foundation for Autism Research (SFARIPA304216, to RW).

Authors' contributions: HDC and RW analyzed and interpreted the mutation data and wrote the manuscript. Both authors read and approved the final manuscript.

Acknowledgements: We are grateful to all of the families at the participating Simons Simplex Collection (SSC) sites, as well as the principal investigators (A. Beaudet, R. Bernier, J. Constantino, E. Cook, E. Fombonne, D. Geschwind, R. Goin-Kochel, E. Hanson, D. Grice, A. Klin, D. Ledbetter, C. Lord, C. Martin, D. Martin, R. Maxim, J. Miles, O. Ousley, K. Pelphrey, B. Peterson, J. Piggot, C. Saulnier, M. State, W. Stone, J. Sutcliffe, C. Walsh, Z. Warren, E. Wijsman). We appreciate obtaining access to phenotypic data on SFARI Base. Approved researchers can obtain the SSC population dataset described in this study by applying at https://base.sfari.org. We are grateful to the Prader-Willi Association of Alberta for their donation in support of our research on autism spectrum disorders. 


\section{Figure Legends.}

Figure 1. Distribution of BMI-Z versus age in the SSC.

Figure 2. Behavioral characteristics of very obese probands on the A) Child Behavior Checklist (CBCL), B) autism behavior checklist (ABC), C) Social Responsiveness Scale (SRS), and D) Vineland Adaptive Behavior Scales (VABS). Values that are significantly different from same sex typical weight probands are indicated $(* P \leq 0.01, \# P \leq 0.001)$. Note that higher scores on the CBCL(6-18), $A B C$ and SRS but lower scores on the VABS are indicative of behavioral deficits. Error bars are not shown for clarity.

Figure 3. Frequency of neonatal findings in SSC probands, divided into groups by BMI-Z.

\section{Supplementary Tables.}

Supplementary Table 1 . De novo genetic events detected in very obese probands (BMI-Z $\geq 3$ ).

Supplementary Table 2. Phenotypes associated with de novo mutations in PTK7, MEGF8 and DVL3.

Supplementary Table 3. Phenotypes associated with de novo MUC5B mutations. 


\section{References}

1. Miles JH: Autism spectrum disorders--a genetics review. Genet Med 2011, 13(4):278-294.

2. Stessman HA, Willemsen MH, Fenckova M, Penn O, Hoischen A, Xiong B, Wang T, Hoekzema K, Vives L, Vogel I et al: Disruption of POGZ Is Associated with Intellectual Disability and Autism Spectrum Disorders. Am J Hum Genet 2016, 98(3):541-552.

3. Casanova EL, Sharp JL, Chakraborty H, Sumi NS, Casanova MF: Genes with high penetrance for syndromic and non-syndromic autism typically function within the nucleus and regulate gene expression. Molecular autism 2016, 7:18.

4. Channell MM, Phillips BA, Loveall SJ, Conners FA, Bussanich PM, Klinger LG: Patterns of autism spectrum symptomatology in individuals with Down syndrome without comorbid autism spectrum disorder. Journal of neurodevelopmental disorders 2015, 7(1):5.

5. Maillard AM, Hippolyte L, Rodriguez-Herreros B, Chawner SJ, Dremmel D, Aguera Z, Fagundo AB, Pain A, Martin-Brevet S, Hilbert A et al: 16p11.2 Locus modulates response to satiety before the onset of obesity. Int J Obes (Lond) 2016, 40(5):870-876.

6. Kerr EN, Bhan A, Heon E: Exploration of the cognitive, adaptive and behavioral functioning of patients affected with Bardet-Biedl syndrome. Clin Genet 2015.

7. Dimitropoulos A, Ho A, Feldman B: Social responsiveness and competence in Prader-Willi syndrome: direct comparison to autism spectrum disorder. Journal of autism and developmental disorders 2013, 43(1):103-113.

8. Fountain MD, Aten E, Cho MT, Juusola J, Walkiewicz MA, Ray JW, Xia F, Yang Y, Graham BH, Bacino CA et al: The phenotypic spectrum of Schaaf-Yang syndrome: 18 new affected individuals from 14 families. Genet Med 2017, 19(1):45-52.

9. Soden SE, Saunders CJ, Willig LK, Farrow EG, Smith LD, Petrikin JE, LePichon JB, Miller NA, Thiffault I, Dinwiddie DL et al: Effectiveness of exome and genome sequencing guided by acuity of illness for diagnosis of neurodevelopmental disorders. Science translational medicine 2014, 6(265):265ra168.

10. Schaaf CP, Gonzalez-Garay ML, Xia F, Potocki L, Gripp KW, Zhang B, Peters BA, McElwain MA, Drmanac R, Beaudet AL et al: Truncating mutations of MAGEL2 cause Prader-Willi phenotypes and autism. Nat Genet 2013, 45(11):1405-1408.

11. Dreyer Gillette ML, Borner KB, Nadler CB, Poppert KM, Odar Stough C, Swinburne Romine R, Davis AM: Prevalence and Health Correlates of Overweight and Obesity in Children with Autism Spectrum Disorder. Journal of developmental and behavioral pediatrics : JDBP 2015, 36(7):489-496.

12. Hill AP, Zuckerman KE, Fombonne E: Obesity and Autism. Pediatrics 2015, 136(6):10511061.

13. Jones KB, Cottle K, Bakian A, Farley M, Bilder D, Coon H, McMahon WM: A description of medical conditions in adults with autism spectrum disorder: A follow-up of the 1980s Utah/UCLA Autism Epidemiologic Study. Autism : the international journal of research and practice 2016, 20(5):551-561.

14. Broder-Fingert S, Brazauskas K, Lindgren K, Iannuzzi D, Van Cleave J: Prevalence of overweight and obesity in a large clinical sample of children with autism. Academic pediatrics 2014, 14(4):408-414.

15. D'Angelo CS, Kohl I, Varela MC, de Castro CI, Kim CA, Bertola DR, Lourenco CM, Perez AB, Koiffmann CP: Obesity with associated developmental delay and/or learning disability in patients exhibiting additional features: report of novel pathogenic copy number variants. $\mathrm{Am} J$ Med Genet A 2013, 161A(3):479-486. 
bioRxiv preprint doi: https://doi.org/10.1101/185900; this version posted September 12, 2017. The copyright holder for this preprint (which was not certified by peer review) is the author/funder, who has granted bioRxiv a license to display the preprint in perpetuity. It is made available under aCC-BY-NC-ND 4.0 International license.

16. Ramachandrappa S, Raimondo A, Cali AM, Keogh JM, Henning E, Saeed S, Thompson A, Garg S, Bochukova EG, Brage S et al: Rare variants in single-minded 1 (SIM1) are associated with severe obesity. J Clin Invest 2013, 123(7):3042-3050.

17. Farooqi IS: Defining the neural basis of appetite and obesity: from genes to behaviour. Clinical medicine 2014, 14(3):286-289.

18. Choquet H, Meyre D: Genetics of Obesity: What have we Learned? Current genomics 2011, 12(3):169-179.

19. Schmunk G, Gargus JJ: Channelopathy pathogenesis in autism spectrum disorders. Front Genet 2013, 4:222.

20. De Ferrari GV, Moon RT: The ups and downs of Wnt signaling in prevalent neurological disorders. Oncogene 2006, 25(57):7545-7553.

21. Hormozdiari F, Penn O, Borenstein E, Eichler EE: The discovery of integrated gene networks for autism and related disorders. Genome research 2015, 25(1):142-154.

22. Caracci MO, Avila ME, De Ferrari GV: Synaptic Wnt/GSK3beta Signaling Hub in Autism. Neural plasticity 2016, 2016:9603751.

23. Helfer G, Tups A: Hypothalamic Wnt Signalling and its Role in Energy Balance Regulation. Journal of neuroendocrinology 2016, 28(3):12368.

24. Ye T, Ip JP, Fu AK, Ip NY: Cdk5-mediated phosphorylation of RapGEF2 controls neuronal migration in the developing cerebral cortex. Nature communications 2014, 5:4826.

25. Krumm N, O'Roak BJ, Shendure J, Eichler EE: A de novo convergence of autism genetics and molecular neuroscience. Trends Neurosci 2014, 37(2):95-105.

26. Ross AJ, May-Simera H, Eichers ER, Kai M, Hill J, Jagger DJ, Leitch CC, Chapple JP, Munro PM, Fisher S et al: Disruption of Bardet-Biedl syndrome ciliary proteins perturbs planar cell polarity in vertebrates. Nat Genet 2005, 37(10):1135-1140.

27. Sanders SJ, Murtha MT, Gupta AR, Murdoch JD, Raubeson MJ, Willsey AJ, Ercan-Sencicek AG, DiLullo NM, Parikshak NN, Stein JL et al: De novo mutations revealed by whole-exome sequencing are strongly associated with autism. Nature 2012, 485(7397):237-241.

28. Iossifov I, Ronemus M, Levy D, Wang Z, Hakker I, Rosenbaum J, Yamrom B, Lee YH, Narzisi G, Leotta A et al: De novo gene disruptions in children on the autistic spectrum. Neuron 2012 , 74(2):285-299.

29. Krishnan A, Zhang R, Yao V, Theesfeld CL, Wong AK, Tadych A, Volfovsky N, Packer A, Lash A, Troyanskaya OG: Genome-wide prediction and functional characterization of the genetic basis of autism spectrum disorder. Nature neuroscience 2016, 19(11):1454-1462.

30. Fischbach GD, Lord C: The Simons Simplex Collection: a resource for identification of autism genetic risk factors. Neuron 2010, 68(2):192-195.

31. Simons Simplex Collection [https://sfari.org/]

32. GPF: Genotype and Phenotype in Families

33. Lek M, Consortium EA, al. e: Analysis of protein-coding genetic variation in 60,706 humans. bioRxiv Preprint server 2015, doi: http://dx.doi.org/10.1101/030338.

34. Mi H, Huang X, Muruganujan A, Tang H, Mills C, Kang D, Thomas PD: PANTHER version 11: expanded annotation data from Gene Ontology and Reactome pathways, and data analysis tool enhancements. Nucleic Acids Res 2017, 45(D1):D183-D189.

35. Kerekes N, Tajnia A, Lichtenstein P, Lundstrom S, Anckarsater H, Nilsson T, Rastam M: Neurodevelopmental problems and extremes in BMI. PeerJ 2015, 3:e1024.

36. Goldman S, Wang C, Salgado MW, Greene PE, Kim M, Rapin I: Motor stereotypies in children with autism and other developmental disorders. Dev Med Child Neurol 2009, 51(1):30-38.

37. Kong A, Frigge ML, Masson G, Besenbacher S, Sulem P, Magnusson G, Gudjonsson SA, Sigurdsson A, Jonasdottir A, Jonasdottir A et al: Rate of de novo mutations and the importance of father's age to disease risk. Nature 2012, 488(7412):471-475. 
bioRxiv preprint doi: https://doi.org/10.1101/185900; this version posted September 12, 2017. The copyright holder for this preprint (which was not certified by peer review) is the author/funder, who has granted bioRxiv a license to display the preprint in perpetuity. It is made available under aCC-BY-NC-ND 4.0 International license.

38. DiStefano C, Gulsrud A, Huberty S, Kasari C, Cook E, Reiter LT, Thibert R, Jeste SS: Identification of a distinct developmental and behavioral profile in children with Dup $15 \mathrm{q}$ syndrome. Journal of neurodevelopmental disorders 2016, 8:19.

39. Mervis CB, Klein-Tasman BP, Huffman MJ, Velleman SL, Pitts CH, Henderson DR, Woodruff-Borden J, Morris CA, Osborne LR: Children with 7q11.23 duplication syndrome: psychological characteristics. Am J Med Genet A 2015, 167(7):1436-1450.

40. Sanders SJ, He X, Willsey AJ, Ercan-Sencicek AG, Samocha KE, Cicek AE, Murtha MT, Bal VH, Bishop SL, Dong S et al: Insights into Autism Spectrum Disorder Genomic Architecture and Biology from 71 Risk Loci. Neuron 2015, 87(6):1215-1233.

41. Hippolyte L, Maillard AM, Rodriguez-Herreros B, Pain A, Martin-Brevet S, Ferrari C, Conus P, Mace A, Hadjikhani N, Metspalu A et al: The Number of Genomic Copies at the 16p11.2 Locus Modulates Language, Verbal Memory, and Inhibition. Biological psychiatry 2016, 80(2):129-139.

42. Walters RG, Jacquemont S, Valsesia A, de Smith AJ, Martinet D, Andersson J, Falchi M, Chen F, Andrieux J, Lobbens $\mathrm{S}$ et al: A new highly penetrant form of obesity due to deletions on chromosome 16p11.2. Nature 2010, 463(7281):671-675.

43. Guo H, Peng Y, Hu Z, Li Y, Xun G, Ou J, Sun L, Xiong Z, Liu Y, Wang T et al: Genome-wide copy number variation analysis in a Chinese autism spectrum disorder cohort. Sci Rep 2017, 7:44155.

44. De Rubeis S, He X, Goldberg AP, Poultney CS, Samocha K, Cicek AE, Kou Y, Liu L, Fromer $\mathrm{M}$, Walker $\mathrm{S}$ et al: Synaptic, transcriptional and chromatin genes disrupted in autism. Nature 2014, 515(7526):209-215.

45. Hamdan FF, Srour M, Capo-Chichi JM, Daoud H, Nassif C, Patry L, Massicotte C, Ambalavanan A, Spiegelman D, Diallo O et al: De novo mutations in moderate or severe intellectual disability. PLoS Genet 2014, 10(10):e1004772.

46. Dong S, Walker MF, Carriero NJ, DiCola M, Willsey AJ, Ye AY, Waqar Z, Gonzalez LE, Overton JD, Frahm S et al: De novo insertions and deletions of predominantly paternal origin are associated with autism spectrum disorder. Cell reports 2014, 9(1):16-23.

47. Iglesias A, Anyane-Yeboa K, Wynn J, Wilson A, Truitt Cho M, Guzman E, Sisson R, Egan C, Chung WK: The usefulness of whole-exome sequencing in routine clinical practice. Genet Med 2014, 16(12):922-931.

48. Weihl CC, Pestronk A, Kimonis VE: Valosin-containing protein disease: inclusion body myopathy with Paget's disease of the bone and fronto-temporal dementia. Neuromuscular disorders : NMD 2009, 19(5):308-315.

49. Cornelis MC, Rimm EB, Curhan GC, Kraft P, Hunter DJ, Hu FB, van Dam RM: Obesity susceptibility loci and uncontrolled eating, emotional eating and cognitive restraint behaviors in men and women. Obesity 2014, 22(5):E135-141.

50. Ashburner M, Ball CA, Blake JA, Botstein D, Butler H, Cherry JM, Davis AP, Dolinski K, Dwight SS, Eppig JT et al: Gene ontology: tool for the unification of biology. The Gene Ontology Consortium. Nat Genet 2000, 25(1):25-29.

51. Martinez S, Scerbo P, Giordano M, Daulat AM, Lhoumeau AC, Thome V, Kodjabachian L, Borg JP: The PTK7 and ROR2 Protein Receptors Interact in the Vertebrate WNT/Planar Cell Polarity (PCP) Pathway. J Biol Chem 2015, 290(51):30562-30572.

52. Bunn KJ, Daniel P, Rosken HS, O'Neill AC, Cameron-Christie SR, Morgan T, Brunner HG, Lai A, Kunst HP, Markie DM et al: Mutations in DVL1 cause an osteosclerotic form of Robinow syndrome. Am J Hum Genet 2015, 96(4):623-630.

53. Stittrich AB, Lehman A, Bodian DL, Ashworth J, Zong Z, Li H, Lam P, Khromykh A, Iyer RK, Vockley JG et al: Mutations in NOTCH1 cause Adams-Oliver syndrome. Am J Hum Genet 2014, 95(3):275-284. 
54. Kashevarova AA, Nazarenko LP, Schultz-Pedersen S, Skryabin NA, Salyukova OA, Chechetkina NN, Tolmacheva EN, Rudko AA, Magini P, Graziano C et al: Single gene microdeletions and microduplication of 3p26.3 in three unrelated families: CNTN6 as a new candidate gene for intellectual disability. Mol Cytogenet 2014, 7(1):97.

55. Utami KH, Winata CL, Hillmer AM, Aksoy I, Long HT, Liany H, Chew EG, Mathavan S, Tay SK, Korzh V et al: Impaired development of neural-crest cell-derived organs and intellectual disability caused by MED13L haploinsufficiency. Human mutation 2014, 35(11):1311-1320.

56. $\quad$ Song WJ, Song EA, Jung MS, Choi SH, Baik HH, Jin BK, Kim JH, Chung SH: Phosphorylation and inactivation of glycogen synthase kinase 3 beta (GSK3beta) by dualspecificity tyrosine phosphorylation-regulated kinase 1A (Dyrk1A). J Biol Chem 2015, 290(4):2321-2333.

57. Chen G, Zhang Z, Adebamowo SN, Liu G, Adeyemo A, Zhou Y, Doumatey AP, Wang C, Zhou $\mathrm{J}$, Yan W et al: Common and rare exonic MUC5B variants associated with type 2 diabetes in Han Chinese. PLoS One 2017, 12(3):e0173784.

58. Hoischen A, Krumm N, Eichler EE: Prioritization of neurodevelopmental disease genes by discovery of new mutations. Nature neuroscience 2014, 17(6):764-772.

59. Tang G, Gudsnuk K, Kuo SH, Cotrina ML, Rosoklija G, Sosunov A, Sonders MS, Kanter E, Castagna C, Yamamoto A et al: Loss of mTOR-dependent macroautophagy causes autistic-like synaptic pruning deficits. Neuron 2014, 83(5):1131-1143.

60. Hao YH, Doyle JM, Ramanathan S, Gomez TS, Jia D, Xu M, Chen ZJ, Billadeau DD, Rosen MK, Potts PR: Regulation of WASH-dependent actin polymerization and protein trafficking by ubiquitination. Cell 2013, 152(5):1051-1064.

61. Glessner JT, Wang K, Cai G, Korvatska O, Kim CE, Wood S, Zhang H, Estes A, Brune CW, Bradfield JP et al: Autism genome-wide copy number variation reveals ubiquitin and neuronal genes. Nature 2009, 459(7246):569-573.

62. Chahrour MH, Yu TW, Lim ET, Ataman B, Coulter ME, Hill RS, Stevens CR, Schubert CR, Collaboration AAS, Greenberg ME et al: Whole-exome sequencing and homozygosity analysis implicate depolarization-regulated neuronal genes in autism. PLoS Genet 2012, 8(4):e1002635.

63. Simons Foundation Powering Autism Research for Knowledge [https://sparkforautism.org/] 
Fig. 1 Cortes
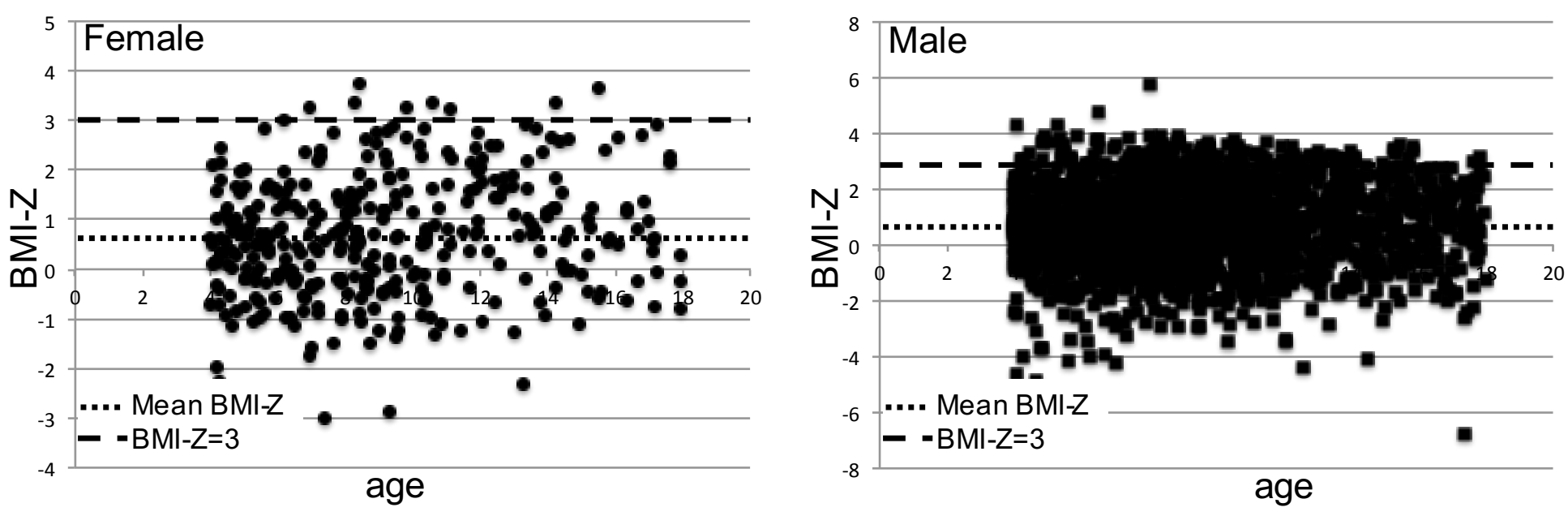
Fig. 2 Cortes
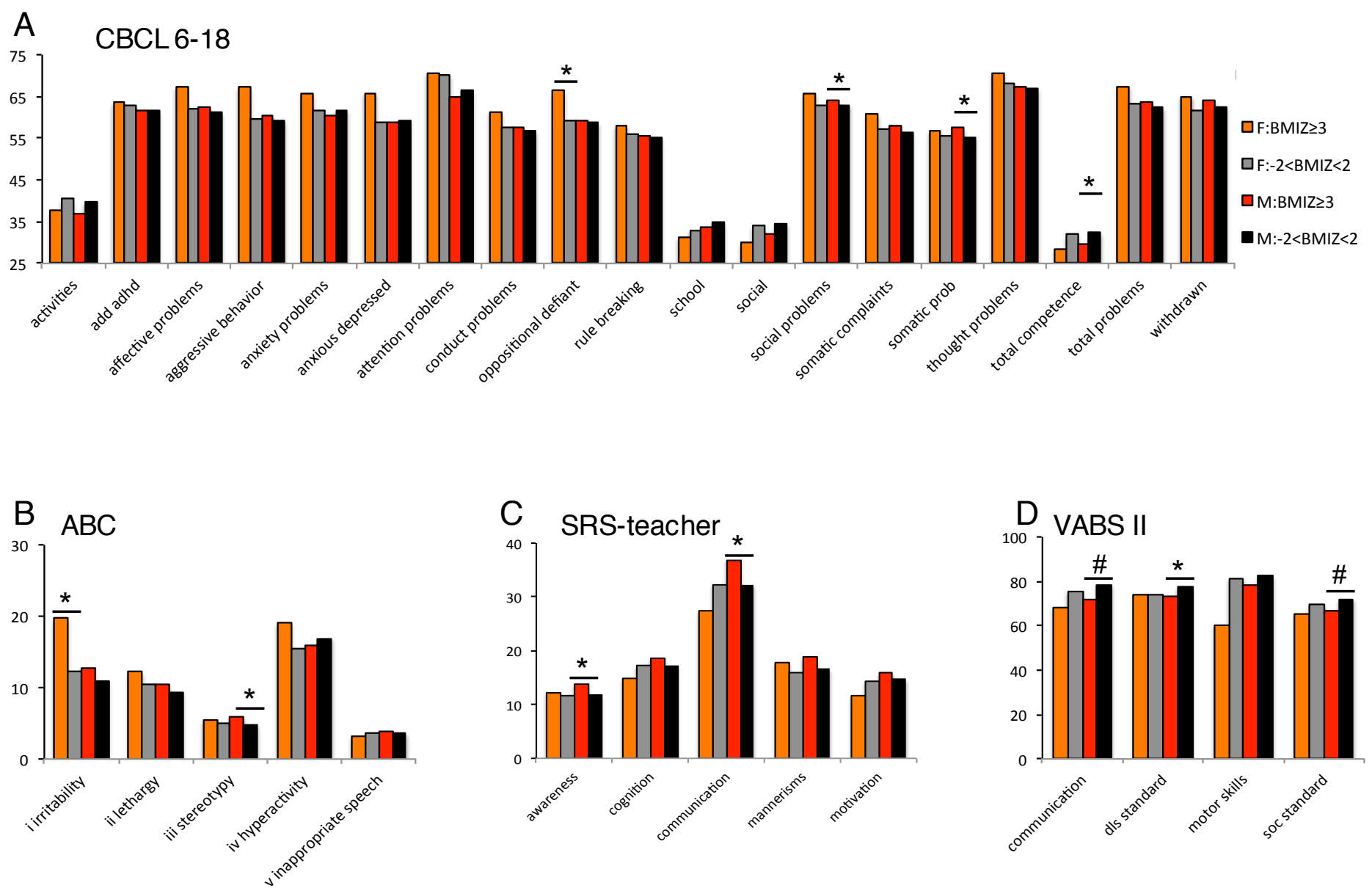
Fig. 3 Cortes

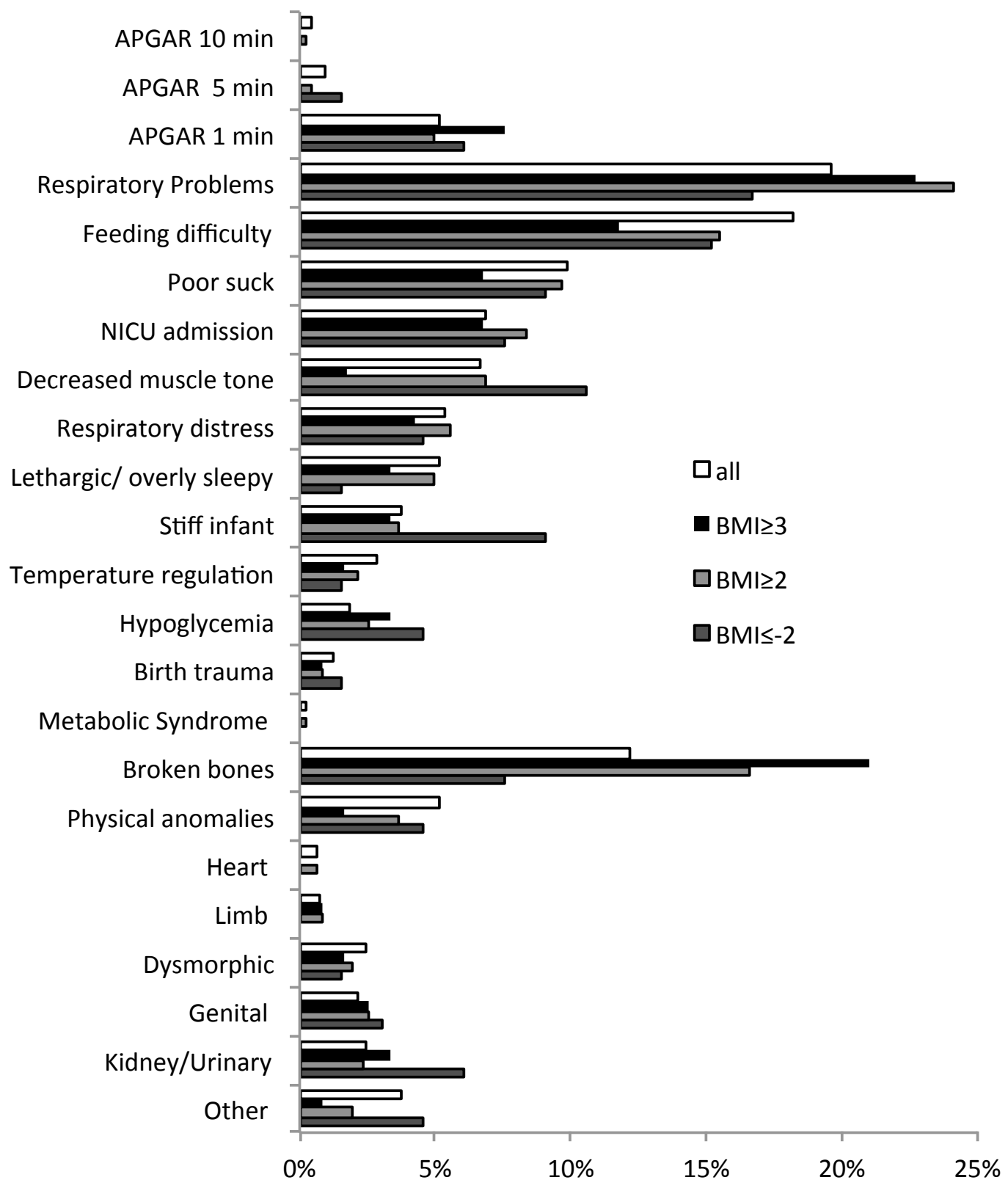




$\begin{array}{ccc}\text { family id } & \text { location variant } \\ 14031 & 2: 38956697-: C N V+ \\ 14114 & 2: 38956697-: C N V+ \\ 13367 & 4: 45410-354: C N V+ \\ 13000 & 5: 814843-82: C N V- \\ 13866 & 5: 98767783-! C N V- \\ 12594 & 7: 72722981-C N V+ \\ 12134 & 7: 73978801-C N V+ \\ 13876 & 8: 35859685-! C N V+ \\ 13646 & 8: 89252843-: C N V- \\ 11718 & 10: 12075111 C N V+ \\ 12437 & 11: 55370916 C N V- \\ 12976 & 11: 55370916 C N V- \\ 12343 & 13: 41104610 C N V+ \\ 13646 & 14: 22538628 C N V- \\ 11501 & 14: 22591454 C N V- \\ 13355 & 15: 26971834 C N V+ \\ 11540 & 16: 29647342 C N V-\end{array}$

worst reques genes

CNV+

CNV+

CNV+

CNV-

CNV-

CNV+

CNV+

CNV+

CNV-

CNV+

CNV-

CNV-

$\mathrm{CNV}+$

CNV-

CNV-

CNV+

CNV-

\section{GALM}

GALM
MIR943;FGFRL1;SLBP;ZNF732;LOC402160;ADD1;LOC100130872;NELFA;LETM1;LO( ZDHHC11

STX1A;WBSCR27;WBSCR22;LAT2;LIMK1;WBSCR28;MIR4284;ABHD11;FKBP6;MIR5 NCF1;PMS2P5;WBSCR16;STAG3L2;GTF2IRD2;GTF2IRD1;GTF2I

IDO2;TM2D2;IDO1;STAR;BAG4;ASH2L;SMIM19;AP3M2;LETM2;IKBKB;HTRA4;WHSC MMP16

FAM45A;FAM45B;SNORA19;NANOS1;EIF3A;GRK5;PRDX3;SFXN4

OR4P4;OR4C11;OR4S2

OR4P4;OR4C11;OR4S2

KBTBD7;KBTBD6;MTRF1;MRPS31;NAA16;MIR621;FOXO1;MIR320D1;SUGT1P3;TPT

GABRA5;GABRG3;GABRB3

MVP;ASPHD1;CORO1A;TBX6;SLX1B-SULT1A4;LOC388242;PRRT2;CDIPT;QPRT;YPEL: proband verbal iq proband non-verbal iq

$\begin{array}{rrr}29 & 53 \\ 20 & 34 \\ 46 & 57 \\ 48 & 29 \\ 67 & 92 \\ 101 & 100 \\ 121 & 127 \\ & 35 & 49 \\ & 101 & 78 \\ 108 & 93 \\ 72 & 78 \\ & 82 & 85 \\ 18 & 42 \\ 101 & 78 \\ 71 & 79 \\ 17 & 43 \\ & 55 & 67\end{array}$


family id location variant in child 13768 4:114277600del(1) prbM 14114 11:428174 ins(T) prbM 12610 17:41197776sub(C->T) prbM 11256 11:68029417del(10) prbM 13809 5:137534409del(2) prbM 12311 2:25505357 ins(T) prbM 13582 11:11730143sub(A->G) prbM 13590 17:28400679del(1) prbM 14287 19:48255803 del(4) prbM 13000 17:8424205 del(1) prbM 13627 1:151378489sub(G->A) prbM $1234017: 58740376 \mathrm{sub}(\mathrm{G} \rightarrow \mathrm{A}) \quad \mathrm{prbF}$ 11842 8:18730165 del(1) prbM 11256 6:43109471 $\operatorname{sub}(\mathrm{C}->\mathrm{T}) \quad \mathrm{prbM}$ 14165 17:49072430del(5) prbM 11160 1:16255763 ins(A) prbF 14147 10:17738825 del(1) prbM $123401: 12175787$ sub(G->A) prbF $\mathrm{prbM}$ $136469: 35060456$ del(5)

\section{worst reques genes} frame-shift ANK2 frame-shift ANO nonsense BRCA1 frame-shift C11ort24 frame-shift CDC23 frame-shift DNMT3A splice-site DSCAML1 frame-shift EFCAB5 frame-shift GLTSCR2 frame-shift MYH10 nonsense POGZ nonsense PPM1D frame-shift PSD3 nonsense PTK7 frame-shift SPAG9 frame-shift SPEN frame-shift STAM splice-site TNFRSF8 frame-shift USP29 frame-shift VCP all effects effect details $5 S$ Cfreq ANK2:frame- 2609/3957|3nan ANO9:frame-416/782 na C11orf24:fral346/449 nan CDC23:frame 239/597 nan DNMT3A:frar 134/166;134, nan DSCAML1:spl1956/2114 nan EFCABS:fram 848/856|14/ GLTSCR2:frar 235/478 nan MYH10:fram.733/1985;72.nan POGZ:nonser 955/1357/Arinan PPM1D:nons 427/605(Trp-nan PSD3:frame-:70/1047 nan PTK7:nonsen 562/1070(Arinan SPAG9:frame 727/1311;73 nan SPEN:frame-:1010/3664 nan STAM:frame-260/540|370nan TNFRSF8:spli:205/484;316, nan USP29:frame652/922 nan VCP:frame-sł515/806 na

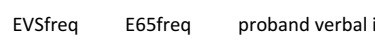

$\begin{array}{llr}\text { EVSfreq } & \text { E65freq } & \text { proband verbal iq } \\ \text { nan } & \text { nan } & 100\end{array}$

100
20
71
98
68
89
79
100
36
48
91
19
15
98
108
99
96
19
29
101 nan nan

nan nan

$\begin{array}{ll}\text { nan } & \text { nan } \\ \text { nan } & \text { nan }\end{array}$

0.01 nan nan

nan nan
nan

nan nan

nan nan

nan

nan nan

nan nan

nan
nan

nan nan tolerance to missense

intolerant

intoleran

intolerant

intolerant

intolerant

intolerant

intoleran

intoleran

intoleran

intolerant

intolerant 


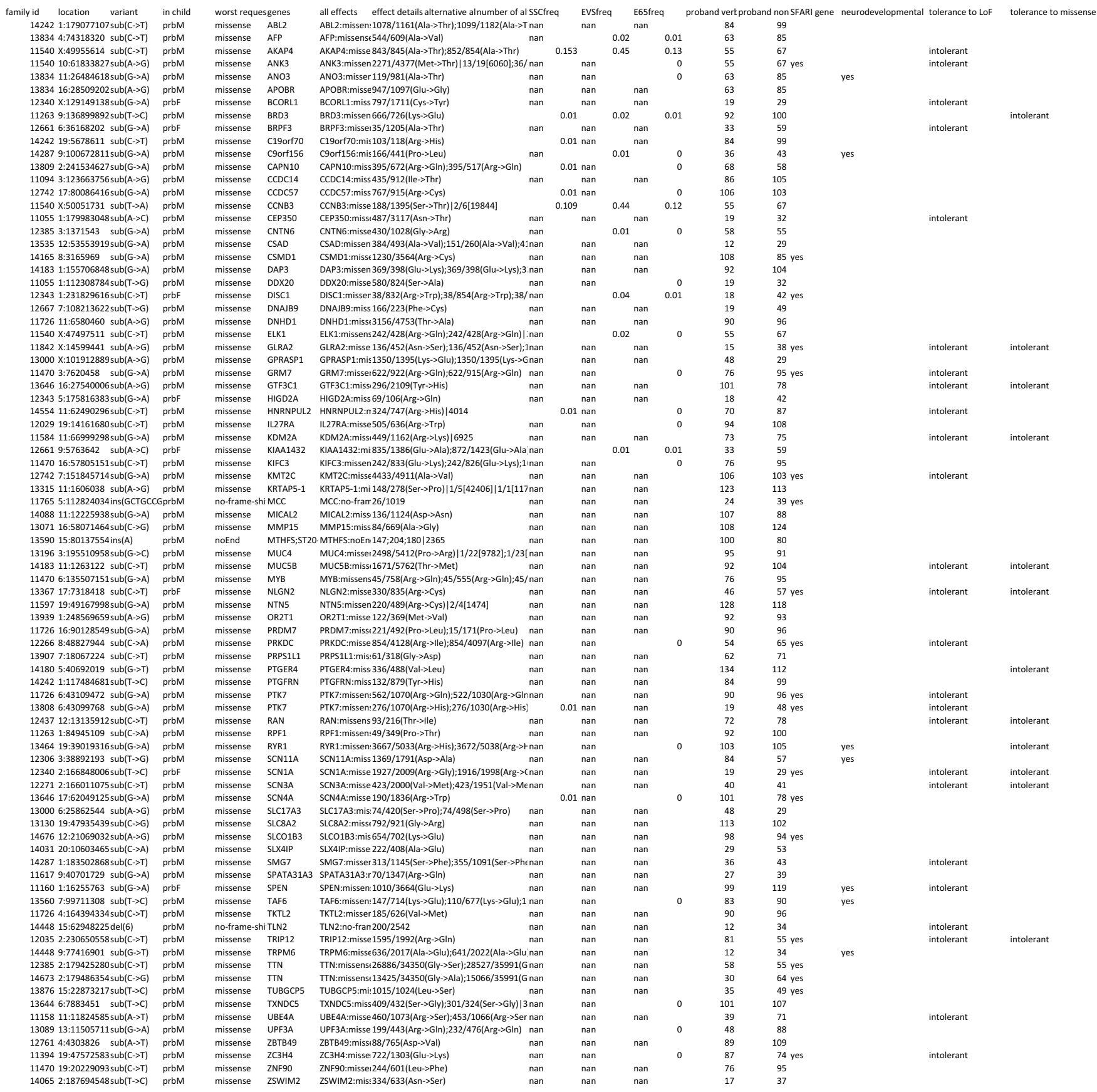


Supplementary Table 2. Mutations in PTK7, MEGF8 and DVL3 in the SSC (rows 1-5, proband IDs are masked) or the Database of Genomic Variants (rows 6-8, Kamisnsky et al., Genet Med. 2011:77784.). The mouse mutant chuzhoi is listed in the bottom row for comparison.

\begin{tabular}{|c|c|c|c|c|c|}
\hline Proband & mutation & BMI-Z & height-Z & $\begin{array}{l}\text { neonatal and other } \\
\text { phenotypes }\end{array}$ & FSIQ \\
\hline 11256.p1 (M) & $\begin{array}{l}\text { PTK7 } \\
\text { nonsense }\end{array}$ & 3.2 & 1.8 & $\begin{array}{l}\text { greater than } 8 \text { ear infections } \\
\text { vision corrected } \\
\text { clumsy }\end{array}$ & 102 \\
\hline 11726.p1 (M) & $\begin{array}{l}\text { PTK7 } \\
\text { R562Q }\end{array}$ & 4.3 & .8 & $\begin{array}{l}\text { respiratory difficulty } \\
\text { frequent otitis media } \\
\text { normal hearing vision }\end{array}$ & 92 \\
\hline 13808.p1 (M) & $\begin{array}{l}\text { PTK7 } \\
\text { R276H }\end{array}$ & 3.0 & .8 & $\begin{array}{l}\text { neonatal genital abnormality, } \\
\text { broken bones } \\
\text { neonatal heart problems, } \\
\text { abnormal eeg } \\
\text { frequent strep throat } \\
\text { normal hearing vision }\end{array}$ & 40 \\
\hline 11798.p1 (M) & $\begin{array}{l}\text { MEGF8 } \\
\text { Q1962G }\end{array}$ & 2.0 & -0.2 & $\begin{array}{l}\text { poor suck, lethargic, floppy, } \\
\text { feeding difficulties, respiratory } \\
\text { difficulties }\end{array}$ & 114 \\
\hline 11242.p1 (M) & $\begin{array}{l}\text { DVL3 } \\
\text { frameshift }\end{array}$ & 2.5 & 0.24 & $\begin{array}{l}\text { poor suck, physical anomalies, } \\
\text { feeding difficulties, genital } \\
\text { abnormalities }\end{array}$ & 94 \\
\hline nsv530893 & $\begin{array}{l}\text { PTK7 } \\
\text { CNVdel } \\
(7.8 \mathrm{Mb}) \\
\text { de novo }\end{array}$ & & & $\begin{array}{l}\text { abnormality of cardiac } \\
\text { morphology; Abnormality of the } \\
\text { skeletal system; Dandy-Walker } \\
\text { malformation; seizure }\end{array}$ & \\
\hline nsv529573 & $\begin{array}{l}\text { PTK7 } \\
\text { CNVdel } \\
2.2 \mathrm{Mb}\end{array}$ & & & intellectual disability & \\
\hline nsv530894 & $\begin{array}{l}\text { PTK7 } \\
\text { CNVdel } \\
4.9 \mathrm{Mb} \\
\end{array}$ & & & $\begin{array}{l}\text { developmental delay and/or other } \\
\text { significant developmental or } \\
\text { morphological phenotypes }\end{array}$ & \\
\hline mouse & $\begin{array}{l}\text { chuzhoi } \\
\text { p.L491_Q } \\
\text { 492insAN } \\
\text { P }\end{array}$ & & & $\begin{array}{l}\text { heterozygote overtly normal, } \\
\text { multiple congenital anomalies in } \\
\text { homozygote }\end{array}$ & \\
\hline
\end{tabular}


Supplementary Table 3. Phenotypes associated with de novo MUC5B mutations in the Simons Simplex Collection.

\begin{tabular}{|c|c|c|c|c|c|}
\hline Proband (sex) & Mutation & BMI-Z & height-Z & neonatal phenotype & FSIQ \\
\hline 11078.p1 (M) & nonsense & 2.93 & .99 & $\begin{array}{l}\text { stiff infant lethargic/overly } \\
\text { sleepy large head circ }\end{array}$ & 29 \\
\hline 14183.p1 (M) & $\mathrm{T} 1671 \mathrm{M}$ & 3.01 & 3.47 & $\begin{array}{c}\text { feeding } \\
\text { clumsy } \\
\text { broken bones } \\
>8 \text { otitis }\end{array}$ & 100 \\
\hline 12779.p1 (M) & P4997L & 1.91 & 1.15 & $\begin{array}{c}\text { feeding } \\
\text { vision corrected }\end{array}$ & 99 \\
\hline 13983.p1 (F) & P3887T & -1.75 & .28 & feeding & 40 \\
\hline 11653.p1 (M) & $\begin{array}{l}\text { del(15) no } \\
\text { frame shift } \\
\text { V2574A } \\
\text { T3883M }\end{array}$ & -.43 & -.77 & stiff infant & 36 \\
\hline 11247.p1 (M) & P4997L & -0.6 & +0.4 & kidney or urinary & 128 \\
\hline 11957.p1 (M) & $\mathrm{C} 4174 \mathrm{~F}$ & 1.6 & -2.0 & physical anomalies, respiratory & 77 \\
\hline 12447.p1 (M) & H4050Q & 0.4 & -0.5 & lethargic & 53 \\
\hline
\end{tabular}

